NASA/TM-2000-209856

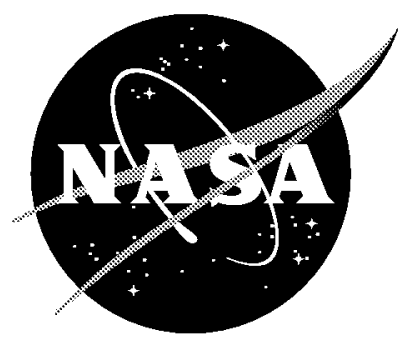

\title{
Residual Strength Analyses of Riveted Lap-Splice Joints
}

B. R. Seshadri and J. C. Newman, Jr.

Langley Research Center, Hampton, Virginia 


\section{The NASA STI Program Office ... in Profile}

Since its founding, NASA has been dedicated to the advancement of aeronautics and space science. The NASA Scientific and Technical Information (STI) Program Office plays a key part in helping NASA maintain this important role.

The NASA STI Program Office is operated by Langley Research Center, the lead center for NASA's scientific and technical information. The NASA STI Program Office provides access to the NASA STI Database, the largest collection of aeronautical and space science STI in the world. The Program Office is also NASA's institutional mechanism for disseminating the results of its research and development activities. These results are published by NASA in the NASA STI Report Series, which includes the following report types:

- TECHNICAL PUBLICATION. Reports of completed research or a major significant phase of research that present the results of NASA programs and include extensive data or theoretical analysis. Includes compilations of significant scientific and technical data and information deemed to be of continuing reference value. NASA counterpart of peer-reviewed formal professional papers, but having less stringent limitations on manuscript length and extent of graphic presentations.

- TECHNICAL MEMORANDUM. Scientific and technical findings that are preliminary or of specialized interest, e.g., quick release reports, working papers, and bibliographies that contain minimal annotation. Does not contain extensive analysis.

- CONTRACTOR REPORT. Scientific and technical findings by NASA-sponsored contractors and grantees.
- CONFERENCE PUBLICATION. Collected papers from scientific and technical conferences, symposia, seminars, or other meetings sponsored or co-sponsored by NASA.

- SPECIAL PUBLICATION. Scientific, technical, or historical information from NASA programs, projects, and missions, often concerned with subjects having substantial public interest.

- TECHNICAL TRANSLATION. Englishlanguage translations of foreign scientific and technical material pertinent to NASA's mission.

Specialized services that complement the STI Program Office's diverse offerings include creating custom thesauri, building customized databases, organizing and publishing research results ... even providing videos.

For more information about the NASA STI Program Office, see the following:

- Access the NASA STI Program Home Page at http://www.sti.nasa.gov

- E-mail your question via the Internet to help@sti.nasa.gov

- Fax your question to the NASA STI Help Desk at (301) 621-0134

- Phone the NASA STI Help Desk at (301) 621-0390

- Write to: NASA STI Help Desk NASA Center for AeroSpace Information 7121 Standard Drive Hanover, MD 21076-1320 
NASA/TM-2000-209856

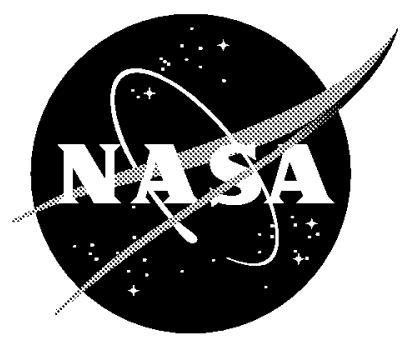

\section{Residual Strength Analyses of Riveted Lap-Splice Joints}

B. R. Seshadri and J. C. Newman, Jr.

Langley Research Center, Hampton, Virginia

National Aeronautics and

Space Administration

Langley Research Center

Hampton, Virginia 23681-2199 
Available from:

NASA Center for AeroSpace Information (CASI)

7121 Standard Drive

Hanover, MD 21076-1320

(301) 621-0390
National Technical Information Service (NTIS) 5285 Port Royal Road

Springfield, VA 22161-2171

(703) 605-6000 


\title{
RESIDUAL STRENGTH ANALYSES OF RIVETED LAP-SPLICE JOINTS
}

\author{
B. R. Seshadri ${ }^{*}$ and J. C. Newman, Jr. \\ NASA Langley Research Center \\ Hampton, Virginia
}

USA

\begin{abstract}
Aging aircraft may develop multiple-site damage (MSD) that can reduce the structural integrity of fuselage structures. The existence of small cracks emanating from adjacent rivet holes in a fuselage lap-splice joint is of major concern. Small collinear cracks greatly reduce the residual strength of a panel with a lead crack. Recent studies predicting the residual strength of flat and curvilinear panels with riveted lap-splice joints gave encouraging results but some difficulties arose in modeling small cracks at rivet-loaded holes. Thus, there was a need to conduct detailed fracture analyses of the crack-linkup phenomenon in lap-splice joints with rivet-loaded fasteners.

The objective of this paper is to analyze the crack-linkup behavior in riveted-stiffened lap-splice joint panels with small MSD cracks at several adjacent rivet holes. Analyses are based on the STAGS (STructural Analysis of General Shells) code with the critical cracktip-opening angle $\left(\mathrm{CTOA}, \Psi_{\mathrm{c}}\right.$ ) fracture criterion. To account for high constraint around a crack front, the "plane strain core" option in STAGS is used. The importance of modeling rivet flexibility with fastener elements that accurately model load transfer across the joint is discussed. Fastener holes are not modeled but rivet connectivity is accounted for by attaching rivets to the sheet on one side of the cracks that simulated both the rivet diameter and MSD cracks. Residual strength analyses made on 2024-T3 alloy (1.6-mm thick) riveted-lap-splice joints with a lead crack and various size MSD cracks were compared with test data from Boeing Airplane Company. Analyses were conducted for both restrained and unrestrained Buckling conditions. Comparison of results from these analyses and results from lap-splice-joint test panels, which were partially restrained against buckling indicate that the test results were bounded by the failure loads predicted by the analyses with restrained and unrestrained conditions.
\end{abstract}

National Research Council Resident Research Associate, NASA Langley Research Center, MS 188E, Hampton, VA 23681 


\section{NOMENCLATURE}

$\begin{array}{ll}\mathrm{B} & \text { specimen thickness, } \mathrm{mm} \\ \mathrm{c}_{\mathrm{i}} & \text { initial half-length of crack, } \mathrm{mm} \\ \mathrm{D} & \text { rivet diameter, } \mathrm{mm} \\ \mathrm{d} & \text { minimum element size along crack line, } \mathrm{mm} \\ \mathrm{E} & \text { Young's modulus, } \mathrm{GPa} \\ \mathrm{h}_{\mathrm{c}} & \text { half-height of plane-strain core, } \mathrm{mm} \\ \mathrm{P} & \text { applied load, } \mathrm{kN} \\ \mathrm{S} & \text { applied stress, } \mathrm{MPa} \\ \mathrm{S}_{\mathrm{f}} & \text { failure stress, MPa } \\ \mathrm{W} & \text { half-width of specimen, } \mathrm{mm} \\ \mathrm{X}, \mathrm{Y}, \mathrm{Z} & \text { Cartesian coordinates } \\ \Delta \mathrm{c} & \text { crack extension, mm } \\ v & \text { Poisson's ratio } \\ \sigma_{\mathrm{ij}} & \text { stress components, MPa } \\ \Psi_{\mathrm{c}} & \text { critical crack-tip-opening angle, degrees }\end{array}$

\section{INTRODUCTION}

The damage tolerant philosophy applied to aircraft fuselage structures requires that the structure retain adequate structural integrity in the presence of discrete source damage or fatigue cracks. Over the years of operation, an aircraft accumulates fatigue damage that may result in fatigue cracks at rivet-loaded joints. Economic factors have also encouraged the use of commercial and military aircraft beyond their original design requirements. Widespread fatigue damage in these aircraft are of great concern because the residual strength of a fuselage structure with a large two-bay crack may be significantly reduced by the existence of small cracks at adjacent rivet holes [1]. Whereas a single large crack in a fuselage structure may produce flapping (resulting in safe decompression), fuselage with a large crack and multiple-site or multiple-element damage (MSD or MED) cracking may not flap, significantly degrading the residual strength of the structure [2,3]. It has become increasingly important to develop methodologies to predict flapping and failure in damaged fuselage structures in the presence of widespread fatigue damage [4]. Development of these methodologies for complex loading is essential to ensure the continued safe operation of aging commercial and military aircraft for the next generation [5]. The approach is (1) to use a finite-element shell code with hierarchical modeling strategies, (2) to use appropriate local fracture criteria to predict progressive failure in complex structures, (3) to conduct material and geometric nonlinear analyses of stiffened shells subjected to complex 
loading, (4) and to conduct experiments to verify analyses and to identify critical behavioral characteristics.

This paper presents recent results from nonlinear fracture simulations on rivetedstiffened lap-splice joints. In 1992, Maclin [3] conducted a series of tests on flat rivetedstiffened panels to study the performance of structural details in older airplanes relative to the pressurized fuselage sections. The study was initiated at Boeing to find out the degree to which structural integrity is maintained after the development of MSD. Flat panels were used in the test program to obtain the probable effects on residual strength of a common scenario -- small fatigue cracks in a row of fastener holes. The expectation was that the flat panels would give some indication on the effects of MSD, while avoiding the time of testing curved fuselage panels. Since then, testing [6] and analyses [7] have shown that the effects of MSD on residual strength are nearly the same for flat and curved panels. Several different crack configurations were considered: (1) a wide $M(T)$ specimen $(2 \mathrm{w}=1219 \mathrm{~mm})$ containing a large crack at the center, $(2)$ a wide $M(T)$ specimen $(2 \mathrm{w}=1219 \mathrm{~mm})$ with a large crack and a riveted hat stiffener parallel to the crack plane (no-load-transfer panel), and (3) wide riveted-stiffened lap-splice joint (load-transfer) panels with a large crack and various size MSD cracks emanating from several adjacent rivet holes. All of these panels were tested with partial anti-buckling guide plates (only positioned along the cracked lapjoint region) to prevent buckling during the course of loading. The authors have noticed that it is very difficult to prevent total buckling of large, cracked panels with partial guide plates. Thus, the panels tested with only partial guide plates may have been buckling to some extent during the course of testing.

The objective of this paper is to present results of analyses that characterize the cracklinkup behavior in riveted-stiffened lap-splice joint panels with small MSD cracks at several adjacent rivet holes. Analyses are based on the STAGS (STructural Analysis of General Shells) code $[8,9]$ with the critical crack-tip-opening angle $\left(\right.$ CTOA, $\left.\Psi_{c}\right)$ fracture criterion. To account for high constraint around a crack front, the "plane strain core" $\left(h_{c}\right)$ option in STAGS is used. The importance of modeling rivet flexibility with fastener elements that accurately model load transfer across the joint will be discussed. Fastener holes were not modeled but rivet connectivity was accounted for by attaching rivets to the sheet on one side of the cracks that were used to simulate both the rivet diameter and MSD cracks. Analyses were conducted for both restrained and unrestrained models against buckling conditions. Comparisons are made between measured and predicted applied stress against crack extension, crack opening displacement (COD), and crack-out-of-plane displacement (COPD) for specimens tested with and without anti-buckling guides. The influence of multiple-site-damage on the buckling response of lap-splice joint specimens is also studied. 
Residual strength analyses made on 2024-T3 (TL) aluminum alloy (1.6-mm thick) rivetedlap-splice joints with a lead crack and various size MSD cracks are compared with test data from Boeing. Finally, the ability of the STAGS shell code and the CTOA fracture criterion to predict the influence of buckling on stable tearing behavior in riveted lap-splice joint panels is studied.

\section{MATERIAL AND SPECIMEN CONFIGURATIONS}

Analyses were conducted on middle-crack tension $\mathrm{M}(\mathrm{T})$ specimens, a riveted-stiffened panel with a single crack, and riveted-stiffened lap-splice-joint panels with a large crack and various sizes of multiple-site-damage (MSD) cracks at adjacent rivet holes. All of the specimens were subjected to remote tension and had partial anti-buckling guides along the crack plane to prevent some buckling. The materials studied in the present study were aluminum alloy 2024-T3 bare (sheet) and 7075-T6 clad (stiffener). The material stressstrain behavior was approximated by piece-wise-linear curves and they are given in Table 1 .

\section{STAGS FINITE-ELEMENT ANALYSES}

The STAGS finite-element shell code [8,9] and the critical crack-tip-opening angle (CTOA) failure criterion were used to model stable tearing of cracks in lap-splice joint panels. The critical CTOA $\left(\Psi_{\mathrm{c}}\right)$ and the plane-strain core height $\left(\mathrm{h}_{\mathrm{c}}\right)$ for the thin-sheet 2024 alloy were determined from failure loads on middle-crack tension specimens that were restrained from buckling [10]. The fracture constants were then used with the STAGS code to predict the fracture behavior of the riveted-stiffened lap-splice joint panels that were either restrained or unrestrained against buckling. Rivet connectivity, rivet yielding, stiffener yielding, out-of-plane buckling, and stiffener-sheet connectivity were modeled during the stable tearing process. Single cracks and MSD cracks at simulated rivet holes were considered.

STAGS is a finite element program for the analysis of general shell-type structures [8,9]. The program has several types of analysis capabilities (static, dynamic, buckling, crack extension, material nonlinear and geometric nonlinear behavior). STAGS has crack extension capability based on the critical crack-tip-opening angle or displacement (CTOA or CTOD) criterion [10], the $\mathrm{T}^{*}$-integral [11] and the traditional $\mathrm{K}_{\mathrm{R}}$-curve. In the current study, quadrilateral shell elements with 6 degrees-of-freedom per node (three displacements and three rotations) were used in all models. The quadrilateral shell elements under "planestress" conditions were used everywhere in the model except for a "core" of elements along the crack plane that were under "plane strain" conditions [10]. Elastic-plastic material behavior of the sheet and stiffener were approximated by multi-linear stress-strain curves. 
The White-Besseling plasticity theory with a form of kinematic hardening was used to account for yielding and reverse yielding during unloading [8].

\section{Fracture Criterion}

To model the fracture process with the CTOA failure criterion, the finite-element mesh had an array of small elements positioned along the crack plane. All crack configurations analyzed used a minimum crack-tip element size (d) of about 1-mm, along the line of crack extension. Previous parametric and convergence studies showed that a minimum crack-tip element size of 1-mm (linear-strain element) was sufficient to model stable tearing under elastic-plastic conditions [12]. Crack growth was governed by monitoring the critical CTOA $\left(\Psi_{\mathrm{c}}\right)$ at a distance of 1-mm (one element) behind the crack tip. In general, the critical value $\left(\Psi_{\mathrm{c}}\right)$ was determined by matching the average failure load measured on several $\mathrm{M}(\mathrm{T})$ specimens (restrained from buckling), as will be discussed later. Typical finite-element models that were used in the STAGS analyses will be shown later.

\section{Modeling of Stiffeners and Rivets}

Analyses of cracked-stiffened panels by Newman and Dawicke [14] indicated that a refined mesh was required in the region of the rivet connection to maintain proper load transfer. In the present study, models of the riveted-stiffened lap-splice joint panels had elements in the rivet-connection region that were 2-mm square. Larger elements were used away from the rivet connections (or rivet connection region) and away from the crack plane to help reduce the number of degrees-of-freedom. The stiffeners were modeled separately and overlapped the sheet with an offset equal to half sheet thickness plus half stiffener thickness. Rivet holes were not modeled $[7,15]$ but rivet connectivity was modeled. Rivet attachment to the sheet was placed on only one side of the cracks.

Rivet connections between the stiffener and sheet were modeled with fastener elements in STAGS. The fastener elements are non-linear spring elements with six degrees-offreedom (three translations and three rotations). For each degree-of-freedom, the user has to input the non-linear load-displacement curve. Rigid links were used at the end of each fastener to distribute the load transferred across the area of each rivet $[7,15]$. A tight fit between the rivet and hole was assumed. For more information on the fastener element capability in STAGS, refer to Ref. 9.

\section{Modeling Stiffener-Sheet Buckling}

Forman [16] has experimentally shown that buckling has a strong influence on the

residual strength of cracked panels. Seshadri and Newman [17] have demonstrated that 
stable tearing in the presence of buckling can be predicted with STAGS and the CTOA fracture criterion. In the present study, a bifurcation analysis was conducted to determine the first buckling mode shape. This out-of-plane displacement shape and an amplitude of $10 \%$ of the sheet thickness was then introduced as an initial imperfection in the panels for the non-linear analysis.

\section{Modeling of Multiple-Site Damage (MSD) Cracking}

Small MSD cracks at adjacent structural details, such as in a riveted fuselage structure, have a strong influence on residual strength, (see Swift [1] and Broek et.al [13]). The MSD crack sizes in the tests from Ref. 2 ranged from 0.35 to $1.3 \mathrm{~mm}$ in length measured from the rivet holes. Because some MSD crack sizes were smaller than the minimum element size, the rivet holes were not modeled but rivet connectivity was modeled. To model the holes and MSD cracks, the nodes along the symmetric plane over the diameter of the hole and MSD cracks were free to displace. Thus, the hole and MSD cracks were modeled as a "crack". One test was also conducted without MSD with only lead crack and rivet-loaded holes. Here the riveted-loaded holes were modeled in two ways. First, the rivet hole was treated as a crack with a length equal to the hole diameter. In the second case, the rivets were treated as tight rivets and modeled only as normal rivet-to-sheet connections using rigid links.

The lead crack and MSD cracks had a constant tearing angle $\left(\Psi_{\mathrm{c}}\right)$ from initiation of tearing to linkup or failure. Crack linkup occurred under constant $\Psi_{\mathbf{c}}$ conditions for all crack tips. Thus, the cracks coalesced with each other always maintaining a constant tearing angle. An option to have a crack-initiation displacement $\left(\delta_{\mathrm{i}}\right)$, or initiation angle $\left(\Psi_{i}\right)$, different than the tearing angle $\Psi_{\mathrm{c}}$ has also been added to the STAGS code [9]. This option can be used to simulate fracture of "sawcuts" for stable tearing cracks [14].

\section{Modeling of Crack-Tip Constraint}

A concept of defining plane-strain elements around the crack-front region [10] was adopted to simulate three-dimensional constraint conditions around a crack front caused by stress triaxility. Previous analyses of wide flat panels [18] have shown that the highconstraint conditions around a crack front, like plane strain, must be modeled in order for the critical CTOA criterion to predict wide panel failure from small laboratory tests. The plane-strain core capability has been added to the STAGS code [9]. The plane-strain core is defined as a strip of plane-strain elements located parallel to the crack plane and extending a half-length $h_{c}$ perpendicular to the crack. In the present analyses, the core 
height was selected as 1-mm to help fit the failure loads of various width $\mathrm{M}(\mathrm{T})$ specimens, as will be discussed later.

\section{Determination of Critical CTOA and Plane-Strain Core Height}

A critical CTOA $\left(\Psi_{c}\right)$ value was used to model the onset of crack growth and the stable tearing process. This criterion is equivalent to a critical CTOD $\left(\delta_{c}\right)$ value at a specified distance behind the crack tip. At each load increment, the current CTOA was calculated and compared to a critical value $\Psi_{c}$. When the CTOA exceeded the critical value, the crack-tip node was released and the crack was advanced to the next node. This process was continued until crack growth became unstable under load control or until the desired crack length had been reached under displacement control. For multiple-sitedamage cracking analyses, all cracks were controlled by the same critical CTOA at each crack tip.

To carry out stable tearing analysis with STAGS, the critical CTOA which governs the onset of crack growth and the plane-strain core height which simulates the threedimensional constraints around the crack-front region needed to be determined. For this purpose, the load-crack-extension results from the $\mathrm{M}(\mathrm{T})$ specimens (restrained from buckling) were used.

The $\mathrm{M}(\mathrm{T})$ specimen configuration and a typical mesh pattern used in the present study are shown in Figs. 1 and 2, respectively. As the configuration and loading are symmetric, only a quarter of the sheet was modeled, as shown in Figure 2. The one-quarter model shown in Figure 2 was for a specimen with width $2 \mathrm{w}=610 \mathrm{~mm}$ and had 1,495 elements and 2,187 nodes. The minimum crack-tip element size (d) of $1 \mathrm{~mm}$, all along the line of crack extension, was chosen to be the same for all meshes generated for the different crack configurations. In the $\mathrm{M}(\mathrm{T})$ specimen, the normal stress, $\sigma_{\mathrm{Xx}}$, parallel to the crack surface is compressive, as shown in Figure 1. If the specimen is not restrained, then the crack flanks will deform out-of-plane (buckle) and this behavior will greatly reduce the load carrying capacity of the panel.

The failure stress $S_{f}$ for various $M(T)$ specimens is shown in Figure 3 as a function of the specimen width (2w). The symbols show the test results of specimens with cracklength-to-width $(\mathrm{c} / \mathrm{w})$ ratios of $1 / 3$. Using a critical angle of 5.0 degrees, the failure stresses predicted under plane-stress conditions are shown as the dashed curve; whereas, the predicted results under plane-strain conditions are shown by the dash-dot curve. From these results, it was clear that neither the plane-strain nor the plane stress analyses could capture the experimental trends. For the thin-sheet alloy, the plane stress fracture behavior fell closer to the experimental results. In order to account for three-dimensional constraint 
effects in two-dimensional analyses, a plane-strain core region was defined around the crack tip [10]. Typically the plane-strain core height is equal to or less than the material thickness. The solid curve with the same critical angle and a plane-strain core height of 1 $\mathrm{mm}$ captured the experimental trends slightly better than the plane-stress analyses.

The load-against-crack extension results from test of $610-\mathrm{mm}$ wide $\mathrm{M}(\mathrm{T})$ specimens with and without anti-buckling guides are shown by symbols in Figure 4(a). Crack extension is the average crack extension measured at both crack tips. Square and circular symbols represent the tests conducted with guides and the triangles show data where guides were not used and the sheet was allowed to buckle. An angle of $\psi_{\mathrm{c}}=5.0$ degrees was used to fit the average of the experimental results for the $\mathrm{M}(\mathrm{T})$ specimens with guides. The dashed curve corresponds to the fracture simulation of the specimens that were restrained from buckling. The analysis was then repeated with the same angle but buckling was allowed. The solid curve represents the numerical results when out-of-plane deformations were permitted. Both the tests and numerical results indicated a significant influence of buckling on stable tearing. The residual strength was drastically reduced when the sheet was allowed to buckle. The experimental and numerical results agreed well near the maximum load, but both analyses tended to slightly over predict crack extension in the early stages of crack growth (between crack initiation and maximum load). This behavior is consistent with the general trend that has been observed on many other tests and analyses [19-22]. At first glance, a higher CTOA at initiation than during stable tearing would make the analysis fit the test data better. However, the plastic history generated during fatigue pre-cracking was not modeled because this capability had not been incorporated into STAGS. It was estimated that fatigue pre-cracking would raise the initial portion of the predicted curve by about $10 \mathrm{kN}$ in the early stages of tearing. But fatigue precracking is not expected to influence the failure load because of the large amount of stable tearing. Also, a crack in the thin-sheet material severely tunnels at crack initiation, as much as two times the sheet thickness, so the surface measurement of crack extension is low compared to the interior [18]. These two issues would tend to make the predicted results with a constant CTOA in better agreement with the test data.

Comparison of Measured and Predicted In-Plane Displacements--For the specimen tested with anti-buckling guides, the in-plane crack-opening displacement was measured at the centerline of the crack with a crack-mouth-opening displacement (CMOD) gage. A comparison of applied stress against CMOD from the test (symbols) and the STAGS analysis (solid line) is shown in Figure 4(b). Only test results from one specimen with guides were available for comparison. Due to a malfunction of the data acquisition system, comparison with test data was possible only up to an applied stress of about $130 \mathrm{MPa}$. The 
initial slope of the measured CMOD curve was about 20 percent lower than the numerical analysis. The reason for the discrepancy is unknown. But the numerical analysis agreed well with the elastic theoretical value (dashed-dot line with $E=71.5 \mathrm{GPa}$ ). The upper dashed line shows the maximum failure stress from the test.

Comparison of Measured and Predicted Out-of-Plane Displacements--For the specimen tested without anti-buckling guides, the out-of-plane displacement was measured using a laser gage at every load increment. The crack out-of-plane (or transverse) displacements (COPD) are plotted against applied stress in Figure 4(c). The symbols show the experimental measurements and the solid curve shows the results from the numerical analysis. Both the test and analyses were conducted for unrestrained (buckling) conditions. Here the numerical analyses tended to over predict the COPD at a given applied stress level, especially beyond the maximum applied stress. This may indicate that the planestrain core height needed to be larger than $1 \mathrm{~mm}$. Reference 8 has indicated that the loadCMOD results beyond maximum load were a strong function of the plane-strain core height. Further study is needed to help resolve these discrepancies.

\section{RESULTS AND DISCUSSIONS}

In the following sections, the results from the numerical analyses are compared with the test data reported in Ref. 2 and are discussed in detail. Corresponding to the three specific panel configurations, detailed STAGS analyses were carried out with restrained boundary conditions to simulate the influence of guide plates and with unrestrained boundary conditions to simulate the influence of buckling on residual strength of the panels. The effects of having a hat-stiffener (parallel to the crack plane) and riveted fasteners on the residual strength of the panel are discussed. Finally, the effects of buckling on stable tearing and the influence of multiple-site damage (MSD) cracking on crack growth behavior with and without buckling in riveted-stiffened lap-splice joint specimens are presented.

\section{Fracture Simulations with Cracks}

Prior to testing the riveted-stiffened lap-splice joint panels, a preliminary test was performed on a 1219-mm wide $\mathrm{M}(\mathrm{T})$ specimen [3]. The test data helped in characterizing the fracture behavior of the material used in the lap-splice joint panels. In this section, the numerical results are compared with the preliminary test.

The specimen configuration and finite-element mesh pattern used in the present analysis were similar to those shown in Figs. 1 and 2, respectively. Only the failure stress was available from Ref. 2 and the dashed line in the Figure 5 shows the value. As 
previously determined from the stable tearing analysis, a critical angle of $\Psi_{c}=5.0$ degrees and a plane-strain core height of $h_{c}=1 \mathrm{~mm}$ was used in the numerical analysis. Results of analyses on the 1219-mm wide $\mathrm{M}(\mathrm{T})$ specimens with and without buckling are plotted as applied stress against crack extension in Figure 5. The dashed curve shows the fracture simulation of the specimens where out-of-plane displacements were restrained. The analysis was then repeated with the same angle but buckling was allowed. The solid curve represents the numerical results when out-of-plane deformations were permitted. The numerical results indicated a significant influence of buckling on stable tearing and residual strength. Analyses results bounded the test failure stress (dashed line).

The discrepancy between the analyses and test data may be due to the following reasons. It is suspected that the use of the partial anti-buckling guide system, only along the crack plane, does not totally prevent buckling away from the crack plane. It has been found [23] that it takes a massive guide-plate system to prevent buckling of wide panels with cracks. The specimen must be totally supported from the crack plane to the grip ends with guide plates that have many orders-of-magnitude greater stiffness than the sheet. The authors $[15,17]$ have shown that the STAGS code and the CTOA fracture criterion can predict stable tearing for wide panels under both restrained and unrestrained conditions. It is very difficult to accurately match the contact boundary conditions for a partially supported buckling panel. Thus, it may be better to conduct tests of wide cracked panels without guide plates and use the numerical fracture simulation to obtain material fracture properties. The analyses could then be conducted with restrained conditions to obtain the fracture behavior and stable tearing without the influence of buckling.

\section{Fracture Simulations of Riveted-Stiffened Panels}

The configuration for the riveted-stiffened (no-load-transfer) panel and a typical finite element mesh used in the present study are shown in Figures 6 and 7. The specimen had a hat stiffener made of 7075-T6 clad located along the centerline of the specimen (parallel to the crack plane). The stiffener was connected to the sheet material through a series of rivets spaced about $30.5 \mathrm{~mm}$ apart. Rivets were made of 2024-T4 material and they were $4.8 \mathrm{~mm}$ in diameter. The finite-element mesh shown in Figure 7 had an array of 1-mm size elements all along the horizontal symmetric plane $(\mathrm{Y}=0)$ for stable crack growth analyses. The mesh element pattern used around the crack-tip region is shown in the same Figure. The one-quarter model for this panel had 5,558 elements and 7,372 nodes. A comparison of experimental and numerical results for the no-load-transfer panel is shown in Figure 8. The dashed line shows the experimental failure stress for the partially restrained panel. Solid and dash-dot curves are the analysis results under unrestrained and restrained 
conditions, respectively. The analysis for the unrestrained case predicts a maximum load that is about 3.5 percent higher than the maximum in the test. In contrast to the $M(T)$ specimen results show in Figure 5, the panel with the horizontal stiffener exhibited much less buckling, presumably because the stiffener prevented some in-plane contraction and supported some of the transverse $\sigma_{\mathrm{XX}}$ stresses in the sheet.

\section{Fracture Simulations of Riveted-Stiffened Lap-Splice Joint Panels with MSD}

The typical riveted-stiffened lap-splice joint panel used in the Boeing test program [2] is shown in the Figure 9. The lap joint had three rows of 4.8- $\mathrm{mm}$ diameter rivets with a hat-stiffener riveted to the central rivet row. The rivet pitch in the axial direction is 30.5 $\mathrm{mm}$ and the rivet rows were spaced at $23 \mathrm{~mm}$ apart. The initial damage in the panel consisted of a 356-mm lead crack located at the center of the top row of rivets. Several panels were also tested with various size MSD cracks emanating from adjacent fastener holes, as shown in Figure 10(a). Only the first four rivets immediately ahead of the lead crack had equal MSD crack sizes emanating from each hole. The other rivet holes were pristine. The test specimens had MSD crack sizes ranging from 0.35 to $1.3 \mathrm{~mm}$ in length from each side of a hole.

In the analysis, two cases were considered to simulate the rivets and/or MSD. First, the rivet hole and MSD were approximated by a crack (length of rivet diameter plus MSD sizes), as shown in Figure 10(b). Rivet connections to the sheet were made on only one side of the crack using rigid links [7]. The particular crack length at each rivet would affect load transfer from each sheet layer. Second, for the case of no MSD cracks, rivets were considered either as cracks (length of rivet diameter), see Figure 10(b), or as a tight rivet with rigid links between adjacent sheets, as shown in Figure 10(c). It was expected that the analyses of the configurations shown in Figures 10(b) and 10(c) would bound the behavior for an actual riveted joint.

A typical finite-element mesh used in the analysis of lap-splice joint is shown in the Figure 11. The one-half model had 15,551 elements and 18,915 nodes. The finite-element mesh was a very refined mesh ( $1 \mathrm{~mm}$ size element) around each crack-tip region and all along the crack growth path (assumed to be straight along the rivet row). Around the fasteners, which transfer load from the outer skin to the inner skin, a refined mesh ( $2 \mathrm{~mm}$ in size) was used. The rivets were modeled with fastener elements. The non-linear behavior of the fastener elements was based on the empirical relation developed by Swift [1] and represents the net shear stiffness of the fastener sheet connection and accounts for bearing deformation. The finite-element mesh did not model the fastener holes. Rivet connectivity 
was accomplished by defining rigid links around the fastener to distribute the fastener loads into the skin nodes that are located within the fastener cross-sectional area [7].

Comparison between the test results and fracture simulations on riveted-stiffened, lapjoint panels with and without MSD are shown in Figs. 12 and 13. The upper dashed line in both figures show the test results for the lap joint (partially restrained) with only a lead crack $\left(c_{i}=356 \mathrm{~mm}\right)$. The lower three dashed lines show failure loads extracted from the MSD test panels (partially restrained) from Ref. 2. The three values of MSD (0.6, 1.1 and $1.6 \mathrm{~mm}$ ) were selected to be analyzed because these values could be simulated with the finite-element mesh shown in Figure 11. Because of the 1-mm element size, the 0.6-mm MSD was the smallest MSD size that could be simulated. This size was about one-half of the standard damage-tolerant crack size $(1.27 \mathrm{~mm})$ and was below the current inspection limit for lap-splice joints [24]. The reason for repeating the analysis under both restrained and unrestrained conditions was to find out the bounds on the residual strength for these conditions. As the experiments were conducted under a partial restraint anti-buckling guide system, the exact simulation of the corresponding boundary conditions would have been difficult. But these bounds would define the limits within which the experimental results should fall. In Figs 12 and 13, the load against crack extension for the lead crack as it grows and links up with the MSD cracks are compared with the failure loads for various MSD crack sizes. The solid curve corresponds to the case of no MSD cracks (assumed tight rivets, see Figure 10(c)). The presence of MSD cracks drastically reduces the residual strength of the panel. Larger MSD crack sizes caused a larger reduction in residual strength.

The three lower analysis curves were obtained from models of simulated lap joints with the crack configurations modeled like Figure 10(b). All rivets along the crack line were assumed to be cracks (length of rivet diameter). The results from the restrained analyses (Fig. 12) for MSD cracks matched the test data better than the results from the unrestrained analyses (Fig. 13). The reason may be due to the horizontal stiffener, the lap joint and the partial restraint system increasing the stiffness in the cracked region and all reducing the influence of buckling on residual strength.

Comparison of failure loads of panels with various MSD crack sizes is shown in Figure 14. The test failure loads (open symbols) are plotted against the MSD crack sizes. Analysis results corresponding to the restrained and unrestrained cases are shown by solid circular and square symbols respectively. For the larger MSD crack sizes considered in analyses, the experimental failure loads fell within the bounds of restrained and unrestrained conditions. But for the smaller MSD crack sizes, the test results fell between dotted lines corresponding to tight rivet (see Fig.10(c)) condition for both restrained (solid triangular 
symbol) and unrestrained (solid diamond) models. This can be considered as a first approximation in analyzing very small MSD cracks emanating from fastener holes. Therefore for very small MSD cracks sizes $(<0.6 \mathrm{~mm})$, modeling of rivet hole and fastener contact is very much essential for realistic solution.

\section{CONCLUDING REMARKS}

Results from the analyses of riveted-stiffened lap-splice joint panels were presented and discussed. Fracture simulations of these panels using the STAGS shell code and the critical crack-tip-opening angle (CTOA) fracture criterion produced quite reasonable results when compared with experimental measurements. The numerical analyses predicted the upper and lower bounds on failure loads corresponding to restrained and unrestrained boundary conditions. For most of the cases, the experimental test data (partial restrained against buckling) was within these bounds. The analyses predicted a significant influence of multiple-site damage (MSD) cracking and buckling on residual strength of the panels. Because the analyses were able to predict the failure loads quite accurately, testing of cracked wide panels without anti-buckling guide plates would be recommended. This would reduce the effort and costs involved in testing wide panels and provide tests with known boundary conditions. This study has demonstrated that the STAGS code and the CTOA fracture criterion can serve as an analysis tool for predicting the residual strength of built structures subjected to complex loading conditions.

Table 1--Material stress-strain properties.

\begin{tabular}{|c|c|c|c|}
\hline \multirow{3}{*}{\multicolumn{2}{|c|}{$\begin{array}{l}2024-\mathrm{T} 3(\mathrm{TL}) \\
\mathrm{E}=71.5 \mathrm{GPa} \\
v=0.3\end{array}$}} & \multicolumn{2}{|c|}{ 7075-T6 (LT) Clad } \\
\hline & & $\mathrm{E}=71.5$ & $\mathrm{GPa}$ \\
\hline & & $v=0.3$ & \\
\hline$\varepsilon$ & $\sigma, \mathrm{MPa}$ & $\varepsilon$ & $\sigma, \mathrm{MPa}$ \\
\hline 0.00434 & 311 & 0.00739 & 529 \\
\hline 0.01 & 356 & 0.015 & 543 \\
\hline 0.02 & 387 & 0.03 & 553 \\
\hline 0.04 & 422 & 0.06 & 569 \\
\hline 0.07 & 453 & 0.12 & 576 \\
\hline 0.1 & 470 & 0.2 & 577 \\
\hline 0.16 & 484 & & \\
\hline 0.2 & 485 & & \\
\hline
\end{tabular}




\section{REFERENCES}

[1] Swift, T., "Damage Tolerance in Pressurized Fuselages," New Materials and Fatigue Resistant Aircraft Design, 14th Symposium of the International Committee on Aeronautical Fatigue (ICAF), Ottawa, Canada, June 1987.

[2] McGuire, J. F. and Goranson, U. G., "Structural Integrity of Future Aging Airplanes," International Conference on Aging Aircraft and Structural Airworthiness, C. E. Harris, ed., NASA CP-3160, Washington, D.C., 1992, pp. 33-48.

[3] Maclin, J., "Performance of Fuselage Pressure Structure," International Conference on Aging Aircraft and Structural Airworthiness, C. E. Harris, ed., NASA CP-3160, Washington, D.C., 1992, pp. 67-75.

[4] Harris, C. E. and Heyman, J. S., "Overview of NASA Research Related to the Aging Commercial Transport Fleet," Journal of Aircraft, Vol. 30, No. 1, 1993, pp. 64-68.

[5] Harris, C. E., Newman, J. C., Jr., Piascik, R. and Starnes, J. H., Jr., "Analytical Methodology for Predicting the Onset of Widespread Fatigue Damage in Fuselage Structure," Journal of Aircraft, Vol. 35, No. 2, 1998, pp. 307-317.

[6] Gruber, M. L., Wilkins, K. E. and Worden, R. E., "Investigation of Fuselage Structure Subject to Widespread Fatigue Damage," Proceedings of FAA-NASA Symposium on the Continued Airworthiness of Aircraft Structures, Atlanta, GA, 1996, pp. 439-459.

[7] Young, R. D., Rouse, M., Ambur, D. R. and Starnes, J. H., Jr., "Residual Strength Pressure Tests and Nonlinear Analyses of Stringer- and Frame-Stiffened Aluminum Fuselage Panels with Longitudinal Cracks," Second Joint NASA/FAA/DoD Conference on Aging Aircraft, C. E. Harris, Ed., NASA CP-1999-208982, Williamsburg, VA., 1998, pp. 408-426.

[8] Almroth, B.; Brogan, F. and Stanley, G., "User's Manual for STAGS", NASA CR 165670, 1978.

[9] Rankin, C. C., Brogan, F. A., Loden, W. A. and Cabiness, H. D., "STAGS User Manual - Version 2.4," Lockheed Martin Advanced Technology Center, Report LMSC P032594, 1997. 
[10] Newman, J. C., Jr., Booth, B. C. and Shivakumar, K. N., “An Elastic-Plastic Finite Element Analysis of the J-Resistance Curve using a CTOD Criterion," Fracture Mechanics: Eighteenth Symposium, ASTM STP 945, D. T. Read and R. P. Reed, Eds., 1988, pp. 665-685.

[11] Atluri, S. N. and Tong, P., "Computational Schemes for Integrity Analyses of Fuselage Panels in Aging Airplanes," Structural Integrity of Aging Airplanes, Springer-Verlag, 1991, pp. 33.

[12] Dawicke, D. S. and Newman, J. C., Jr., "Residual Strength Predictions for MultipleSite Damage Cracking using a CTOA Criterion," Fatigue and Fracture Mechanics: 29th Volume, ASTM STP 1332, T. L. Panontin and S. D. Sheppard, Eds., 1999, pp.815-829.

[13] Broek, D., Thomson, D. and Jeong, D. Y., "Testing and Analysis of Flat and Curved Panels with Multiple Cracks," NASA CP 3274, Part II, September 1994, pp. 963984.

[14] Newman, J. C., Jr. and Dawicke, D. S., "Fracture Analysis of Stiffened Panels under Biaxial Loading with Widespread Cracking," AGARD CP-568, 1995, pp. 3.1-3.16.

[15] Seshadri, B. R., Newman, J. C., Jr, Dawicke, D. S. and Young, R. D. "Fracture Analysis of FAA/NASA Wide Stiffened Panels," Second Joint NASA/FAA/DoD Conference on Aging Aircraft, C. E. Harris, Ed., NASA TM-1998-208976, Williamsburg, VA., 1998, pp. 513-524.

[16] Forman, R. G., "Experimental Program to Determine Effect of Crack Buckling and Specimen Dimensions on Fracture Toughness of Thin Materials," Technical Report AFFDL-TR-65-146, January 1966.

[17] Seshadri, B. R. and Newman, J. C., Jr., "Analyses of Buckling and Stable Tearing in Thin-Sheet Materials," Fatigue and Fracture Mechanics: 29th Volume, ASTM STP 1332, T. L. Panontin and S. D. Sheppard, Eds., 1999, pp.114-134.

[18] Newman, J. C. Jr., Dawicke, D. S. and Bigelow, C.A., "Finite-Element Analyses and Fracture Simulation in Thin-Sheet Aluminum Alloys", Durability of Metal Aircraft Structures, S. N. Atluri et al., Eds., Atlanta, Georgia, 1992, pp. 167-186. 
[19] Kanninen, M., Rybicki, E., Stonesifer, R., Broek, D., Rosenfield, A. and Nalin, "Elastic-Plastic Fracture Mechanics for Two-Dimensional Stable Crack Growth and Instability Problems," ASTM STP 668, 1979, pp. 121-150.

[20] Dawicke, D. S., Sutton, M., Newman, J. C., Jr. and Bigelow, C. A., "Measurement and Analysis of Critical CTOA for an Aluminum Alloy Sheet," Fracture Mechanics: 25th Volume, ASTM STP 1220, F. Erdogan, Ed., 1995, pp. 358-379.

[21] Dawicke, D. S.; Newman, J. C., Jr. and Bigelow, C. A., "Three-Dimensional CTOA and Constraint Effects during Stable Tearing in a Thin-Sheet Material," Fracture Mechanics: 26th Volume, ASTM STP 1256, W. G. Reuter, J. H. Underwood and J. C. Newman, Jr., Eds., 1995, pp. 223-242.

[22] Newman, J. C., Jr.; Dawicke, D. S.; Sutton, M. A. and Bigelow, C. A., “A Fracture Criterion for Widespread Cracking in Thin-Sheet Aluminum Alloys," Durability and Structural Integrity of Airframes, Vol. I, A. F. Blom, Ed., 1993, pp. 443-468.

[23] Dawicke, D. S., Gullerud, A. S., Dodds, R. H., Jr. and Hampton, R. W., "Residual Strength Predictions with Crack Buckling," Second Joint NASA/FAA/DoD Conference on Aging Aircraft, C. E. Harris, Ed., Williamsburg, VA., 1998, pp. 565574.

[24] Hagemaier, D., Rengel, K., Wincheski, B. and Namkung, M., "Evaluation of the SelfNulling Rotating Eddy Current Probe System," Second Joint NASA/FAA/DoD Conference on Aging Aircraft, C. E. Harris, Ed., Williamsburg, VA., 1998, pp. 252264. 


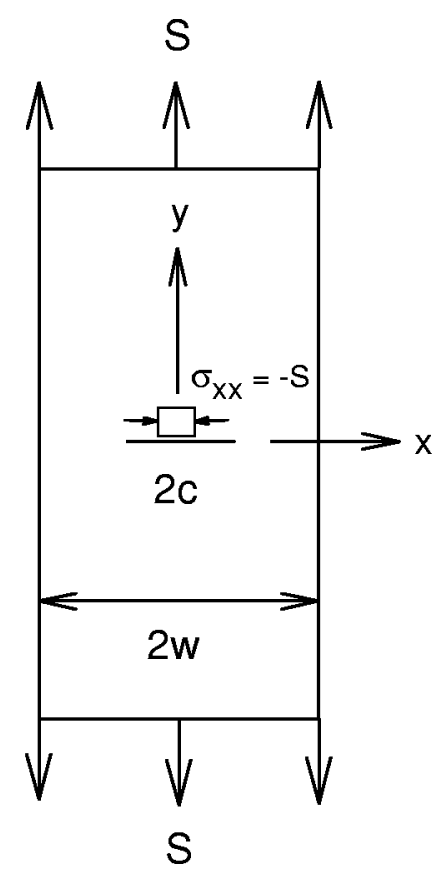

Figure 1 - Middle-crack tension, M(T), specimen.
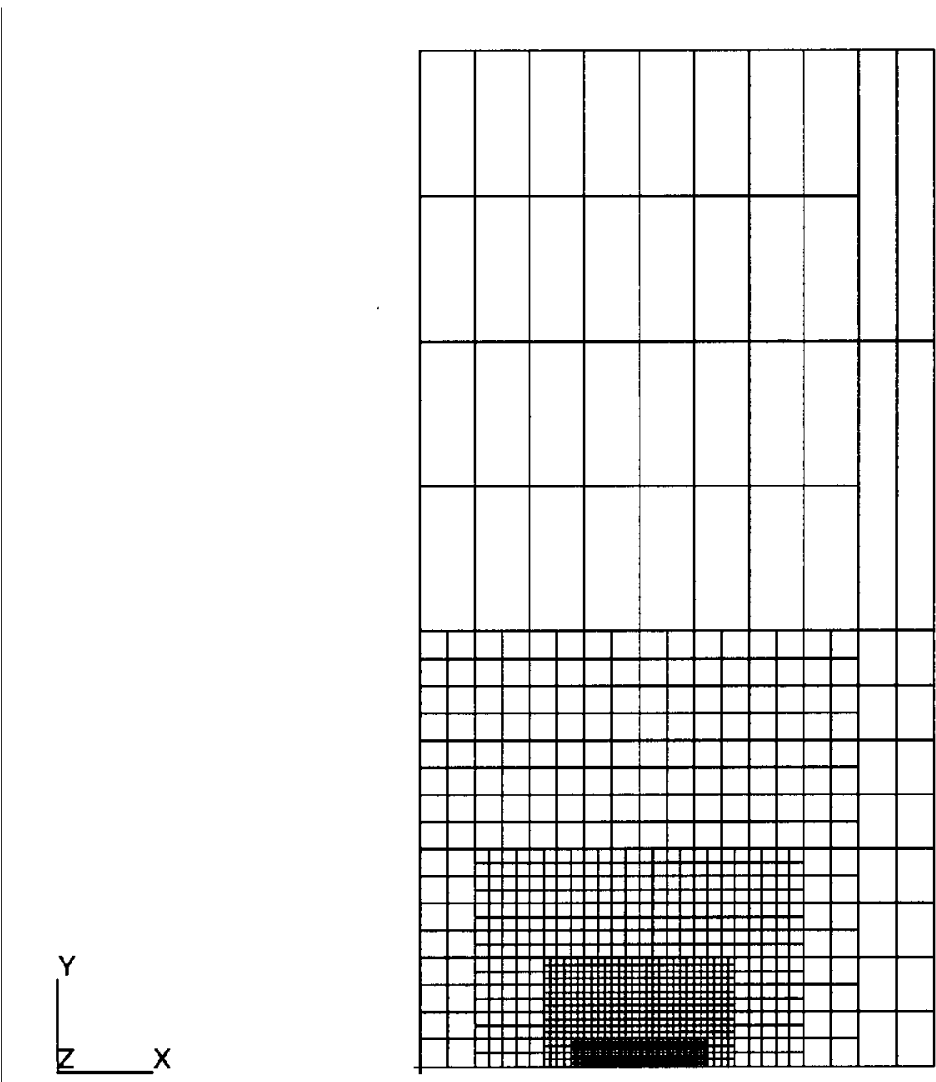

Figure 2 - A typical finite-element model of one-quarter of an $\mathrm{M}(\mathrm{T})$ specimen. 


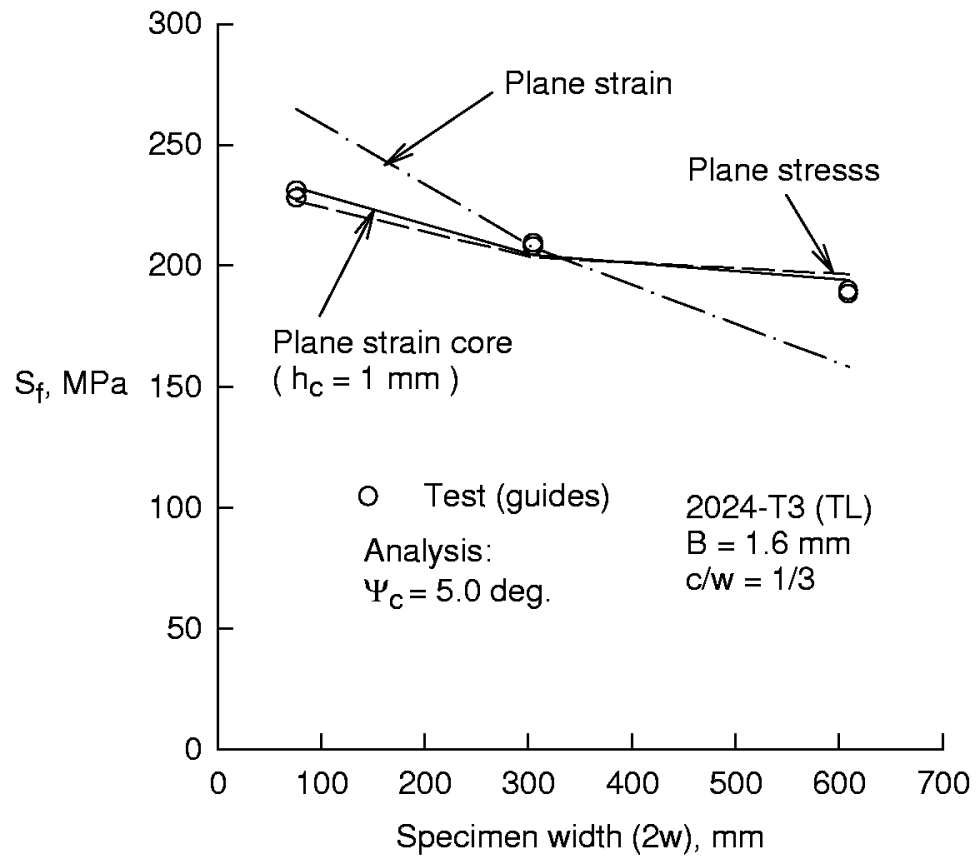

Figure 3 - Measured and calculated failure stress for various width $M(T)$ specimens.

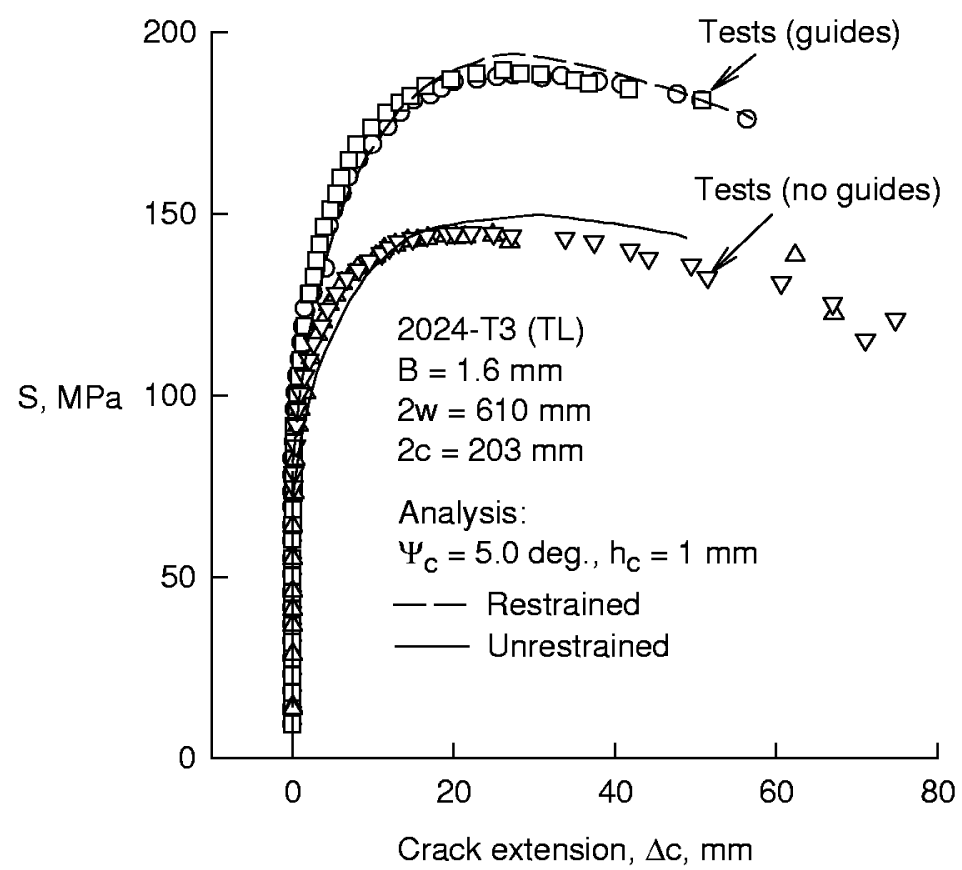

Figure 4(a) - Measured and predicted stable crack growth in $\mathrm{M}(\mathrm{T})$ specimens using CTOA fracture criterion. 


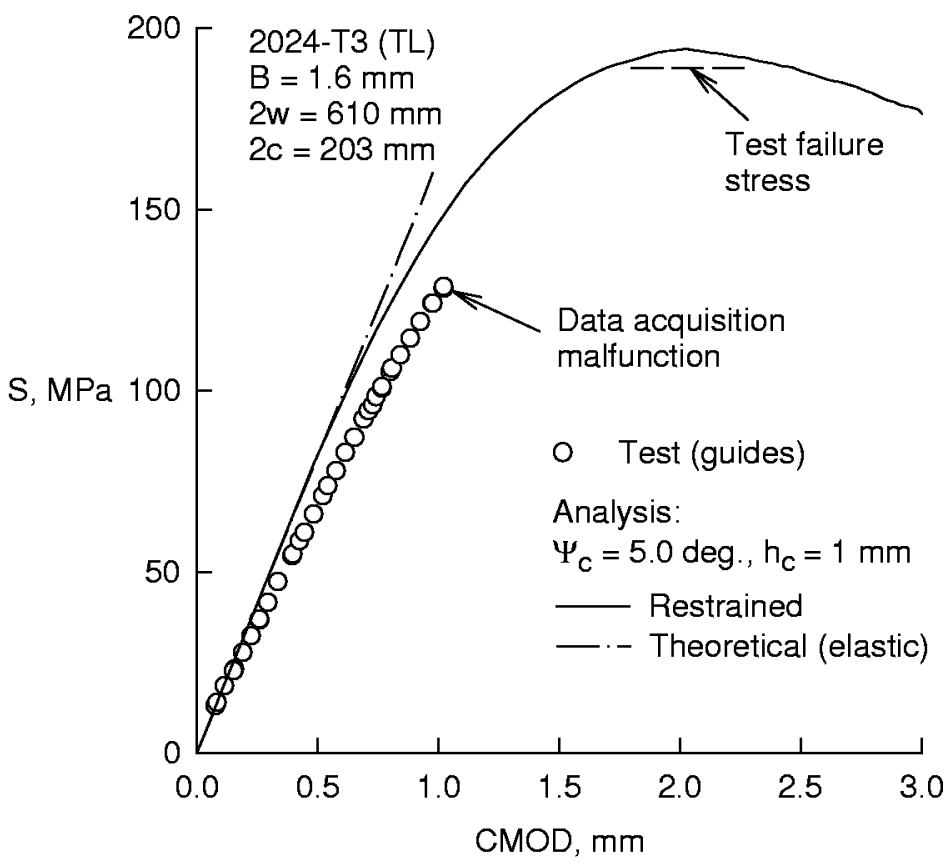

Figure 4(b) - Measured and predicted crack-mouth-opening displacement (CMOD) for $\mathrm{M}(\mathrm{T})$ specimen.

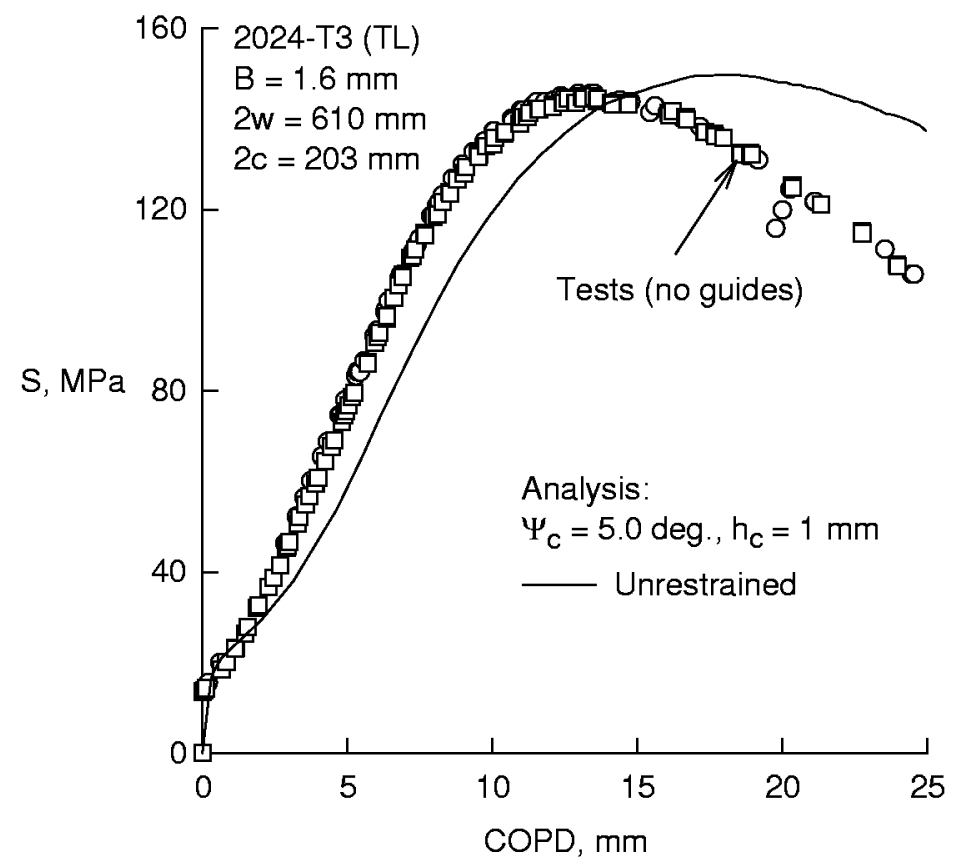

Figure 4(c) - Measured and predicted crack out-of-plane displacement (COPD) for M(T) specimens. 


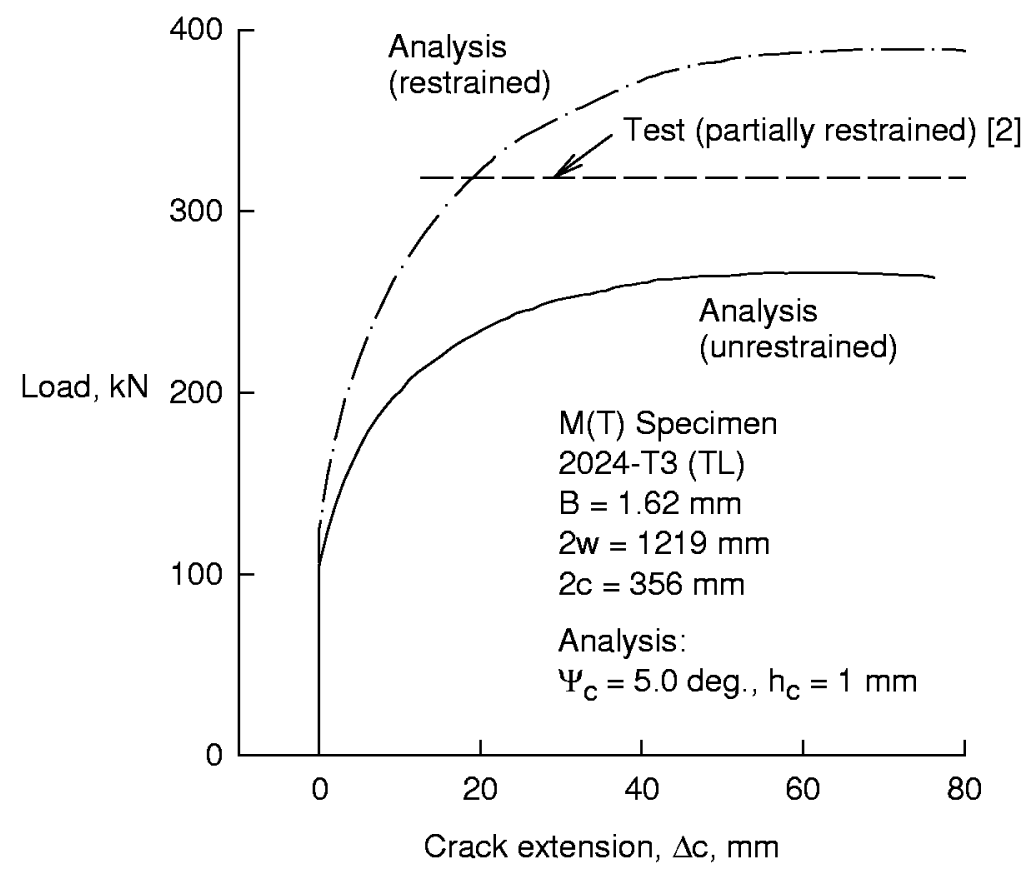

Figure 5 - Measured failure stress and predicted crack extension for $\mathrm{M}(\mathrm{T})$ specimens.

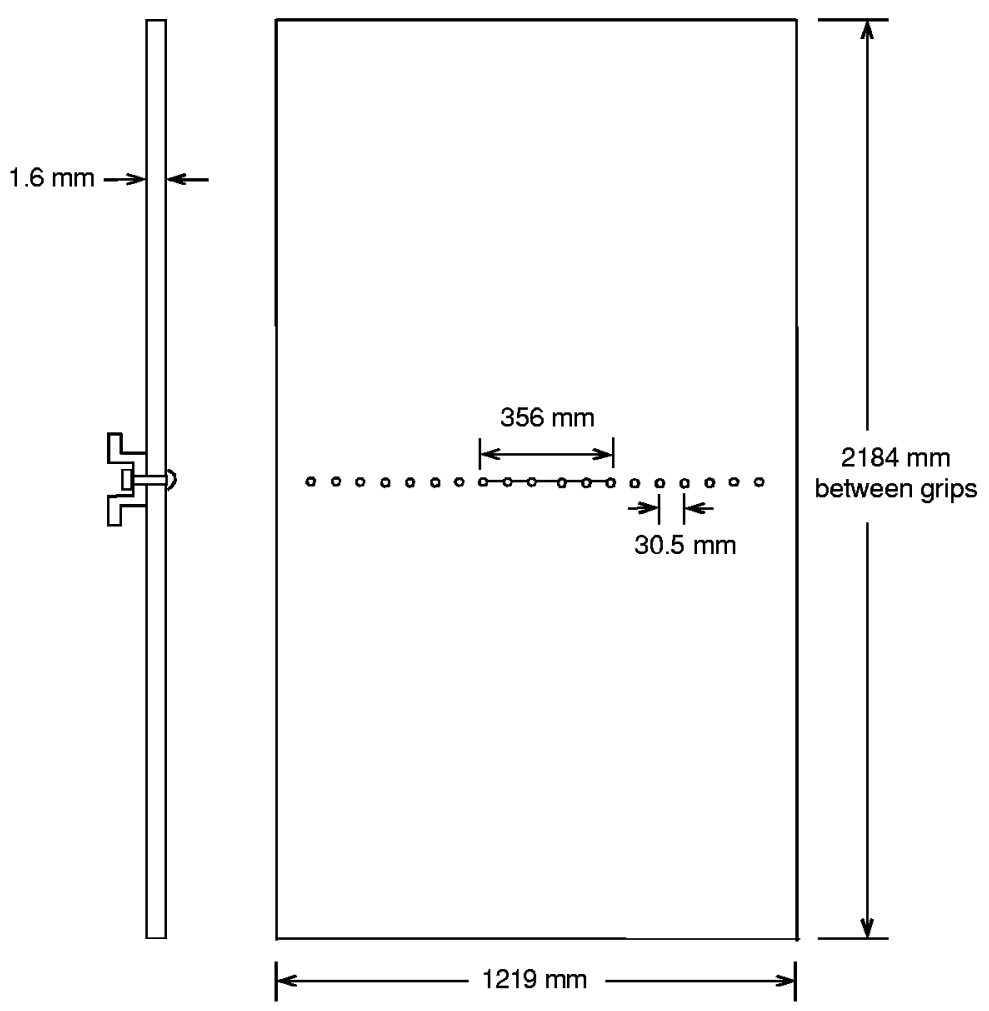

Figure 6 - Riveted and stiffened wide panel with a single crack. 


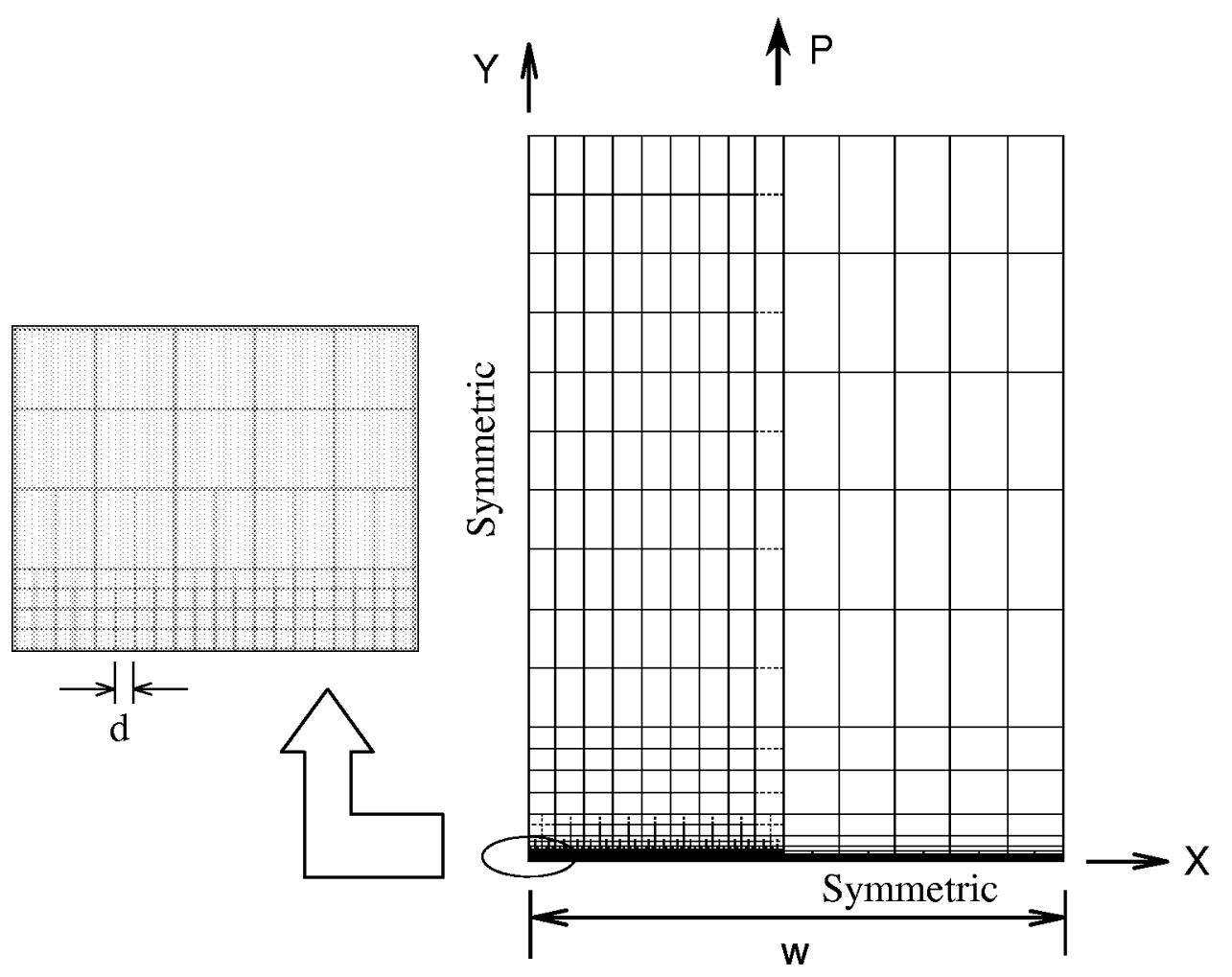

Figure 7 - Typical finite-element model of riveted-stiffened panel.

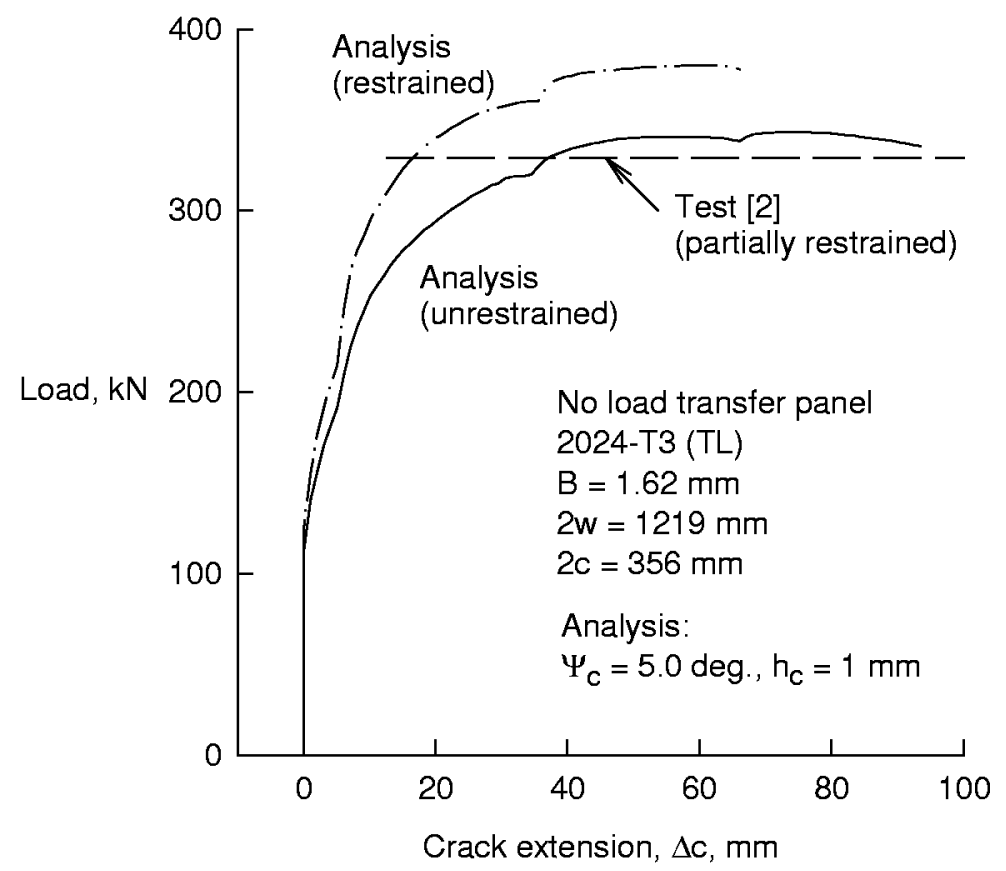

Figure 8 - Measured failure stress and predicted crack extension for wide, riveted-stiffened panel. 

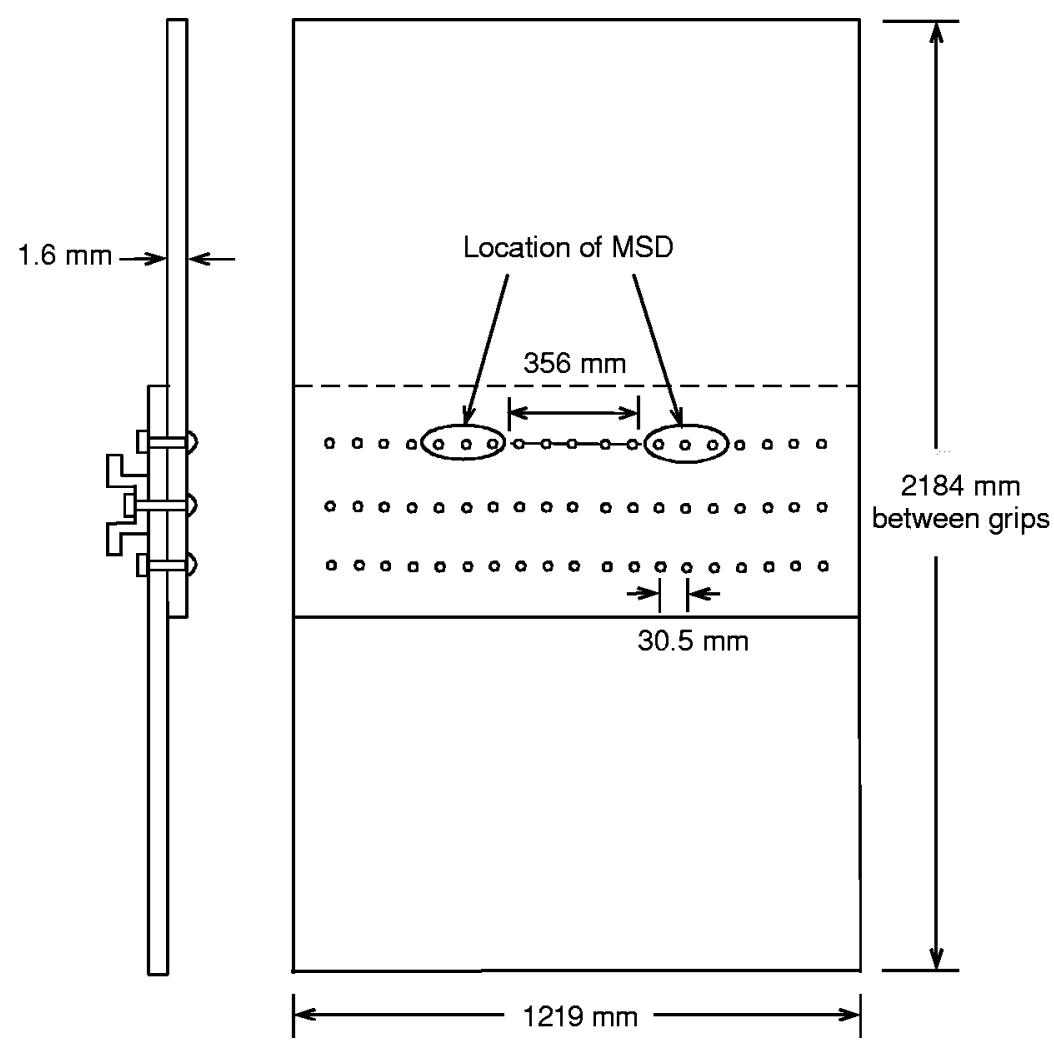

Figure 9 - Typical riveted and stiffened lap-splice joint panel.
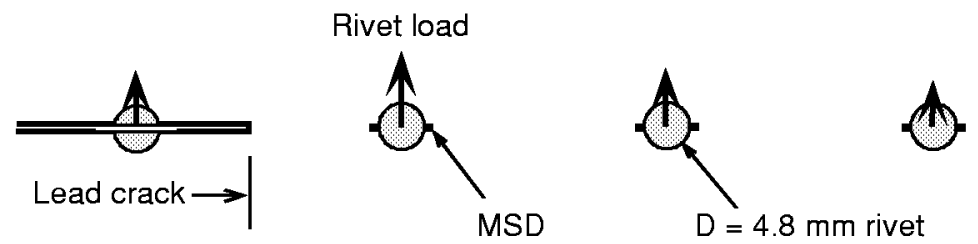

(1)

(a) Schematic of MSD in riveted lap-splice joint

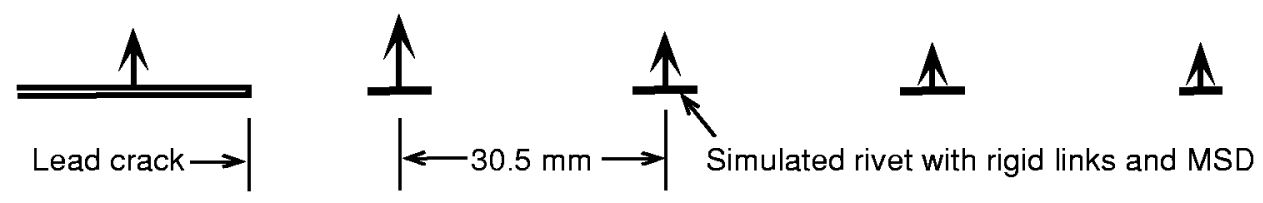

(b) Simulated lead crack and MSD with rivet loading

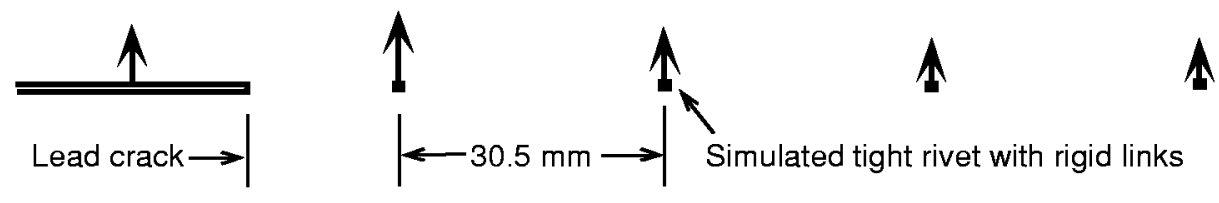

(c) Simulated lead crack and tight rivet

Figure 10 - Schematic of lap-splice joint and simulation methods for rivets and MSD. 


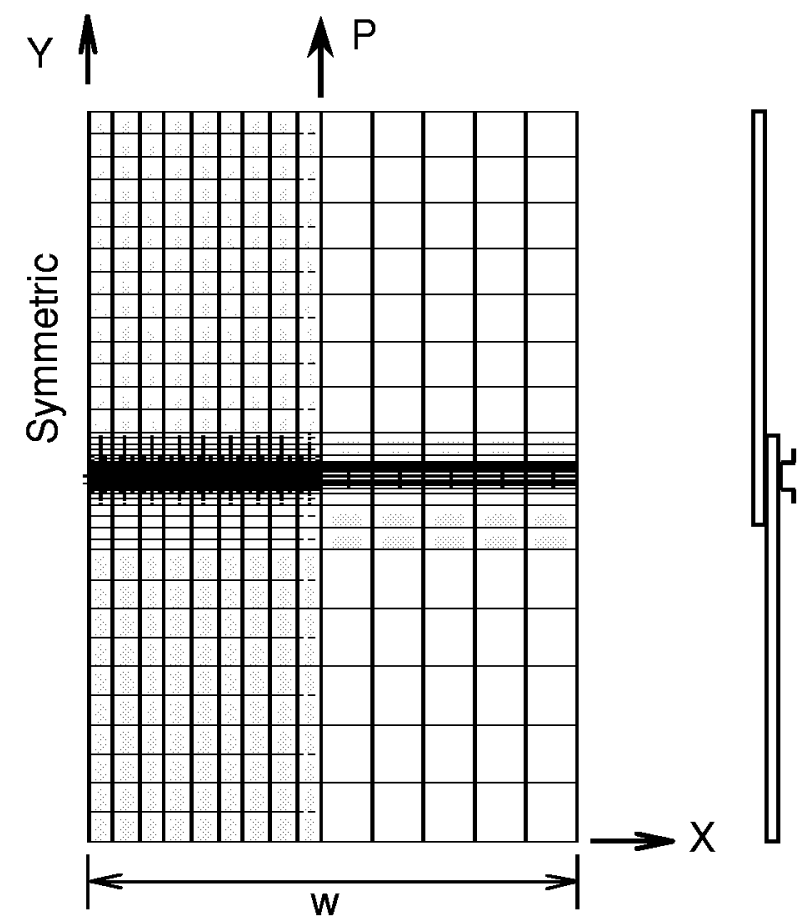

Figure 11 - Typical finite-element model of riveted-stiffened lap-splice joint panel.

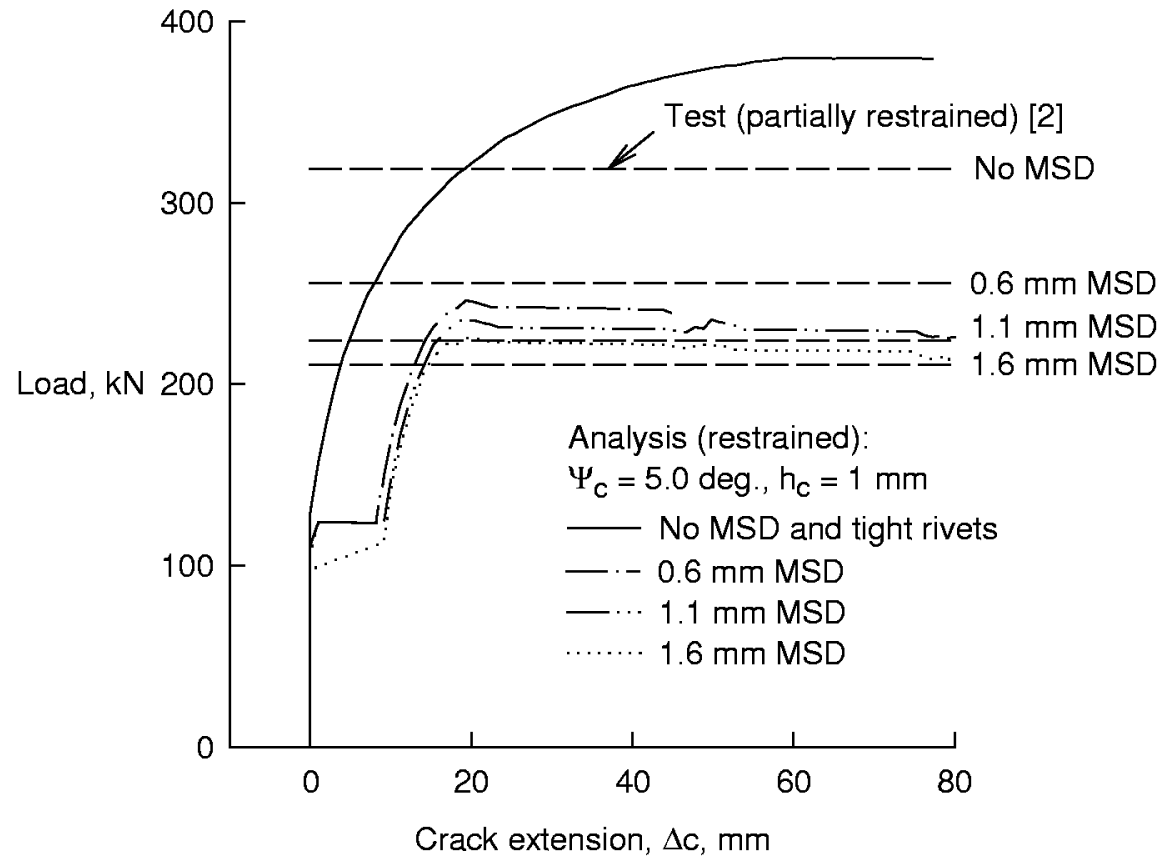

Figure 12 - Measured failure loads and predicted crack extension in wide restrained riveted-stiffened panels with and without MSD. 


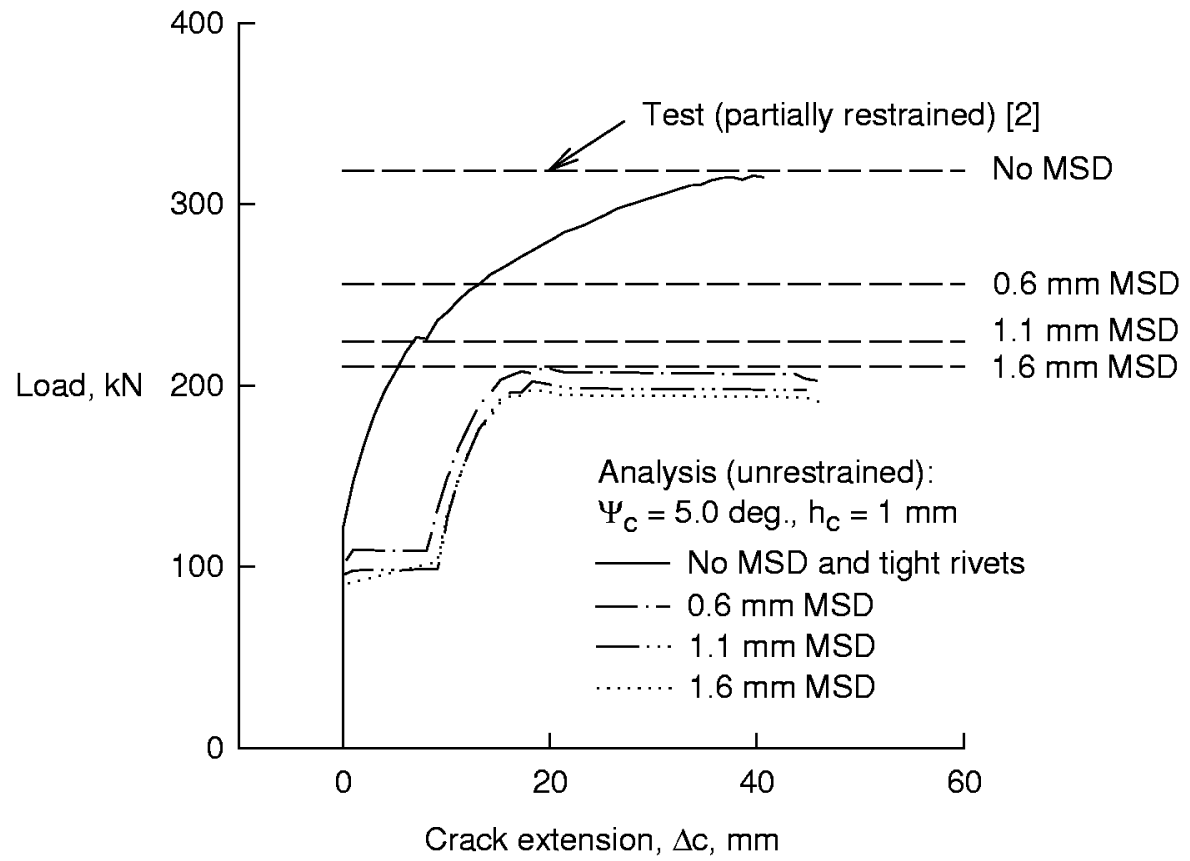

Figure 13 - Measured failure loads and predicted crack extension in wide unrestrained riveted-stiffened panels with and without MSD.

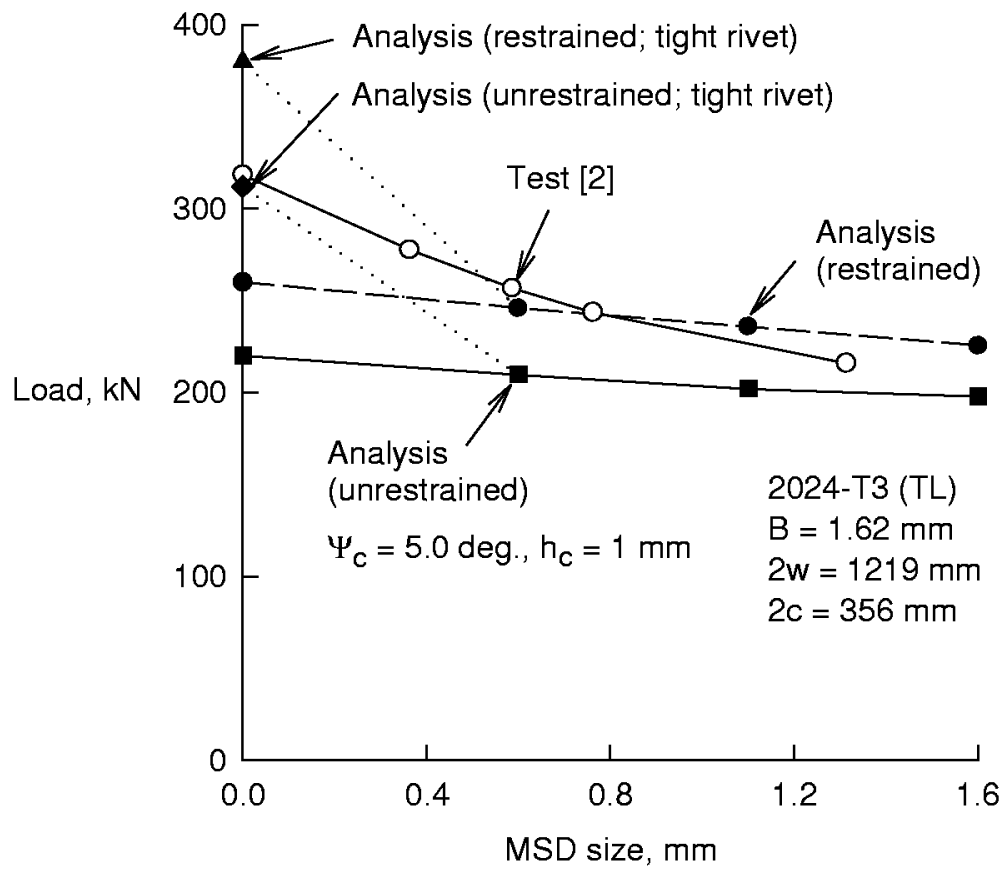

Figure 14 - Measured and predicted failure loads for wide restrained and unrestrained riveted-stiffened panels with MSD. 


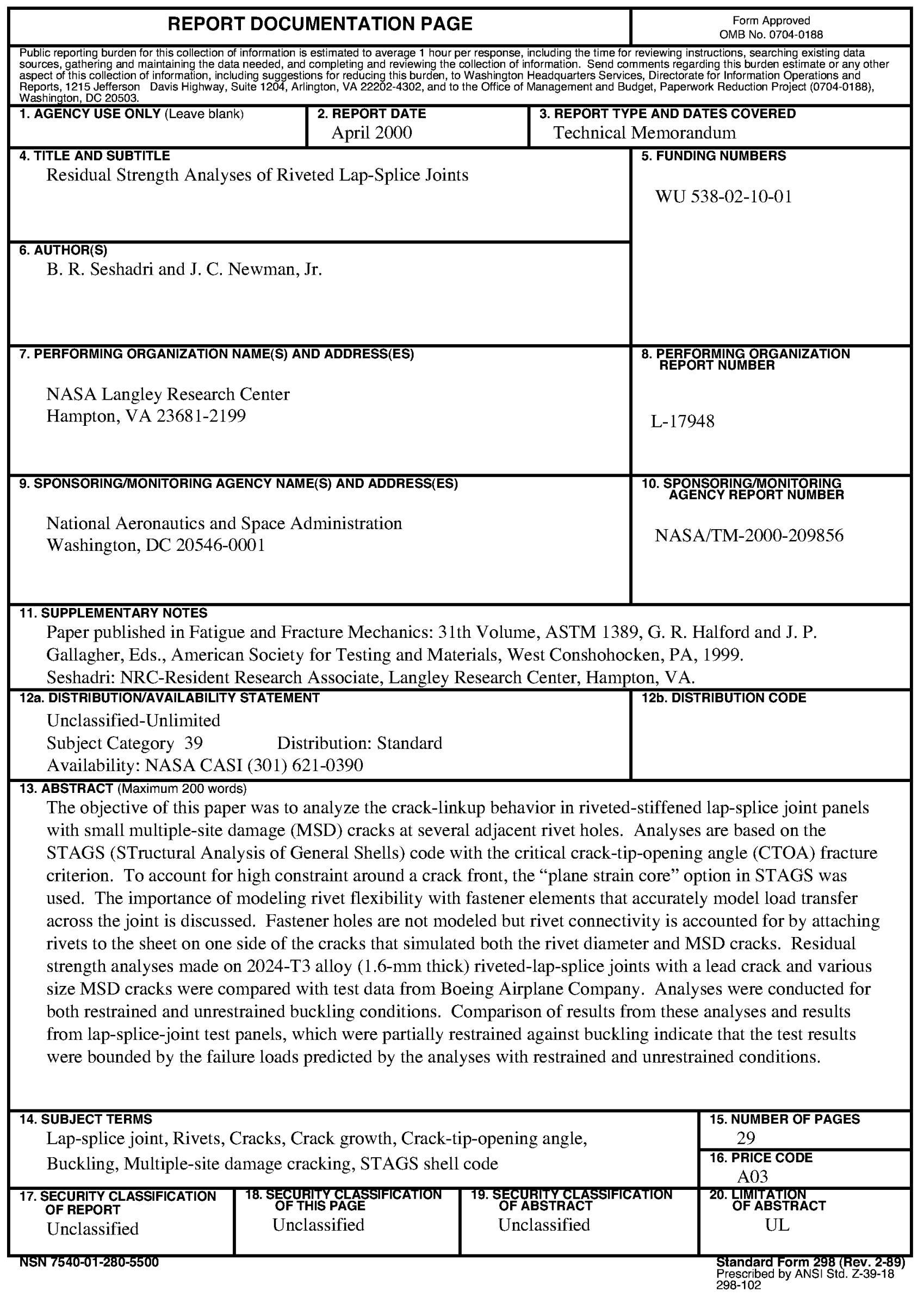

